\title{
Analysis of surface structure of zirconia crystals in case of friction against steel
}

\author{
Valery Alisin ${ }^{1, *}$, Mikhail Borik ${ }^{2}$, Alexey Kulebyakin ${ }^{2}$, Elena Lomonova ${ }^{2}$, and Irina Suvorova ${ }^{3}$ \\ ${ }^{1}$ Mechanical Engineering Research Institute of the Russian Academy of Sciences, Malyi Kharitonevskiy \\ per., 4, Moscow, Russia \\ ${ }^{2}$ Prokhorov General Physics Institute of the Russian Academy of Sciences, 119991, 38 Vavilov st, \\ Moscow, Russia \\ ${ }^{3}$ A.M. Pidhornyi Institute of Mechanical Engineering Problems, 61046, vul. Pozharskogo, 2/10, \\ Kharkiv, Ukraine
}

\begin{abstract}
The article considers the formation of the third body during dry friction of the nanostructured zirconia crystals partially stabilized with yttria against steel. The assumption is substantiated that the tribological properties of the studied friction pair are determined by the properties of the films formed on the surface of the crystals. Friction tests under sliding conditions were performed according to the "disk-finger" scheme. The results of electron microscopic examination of the friction surfaces of crystals are presented. The elemental composition was determined, and the phase composition of the transfer films of various sections of the crystal friction surface was calculated. At high magnifications, it was found that the friction surface of samples with $2-4 \mathrm{~mol} \%$ of $\mathrm{Y}_{2} \mathrm{O}_{3}$ has the sufficiently homogeneous structure of the films with traces of boundaries of smaller particles of the transferred material. Destruction of the friction surface of a sample with a $\mathrm{Y}_{2} \mathrm{O}_{3}$ content of $8 \mathrm{~mol} . \%$ occurs at a deeper level and affects not only the layer of secondary structures, but also the underlying layers of the base material.
\end{abstract}

\section{Introduction}

Ceramic materials based on zirconia are characterized by increased crack resistance, have high wear resistance and strength. Much attention is paid to the study of the nature of friction of zirconium ceramics. In paper [1], the high-speed friction of zirconium ceramics against high-carbon steel was studied. The friction surfaces were studied in terms of chemical composition and mechanical properties. The formation of a transfer film is noted, which includes the oxidation products of ceramics and iron, and which protects ceramics from brittle fracture. The strength properties of zirconium ceramics are influenced by the anisotropy of mechanical properties. It was found [2] that textured structures will have improved fracture toughness and thermal shock resistance. Raman spectroscopy was used to study the effect of zirconium on the properties of silicon ceramics [3]. It is shown that the graphitization of free carbon increases with increasing temperature. A high temperature stability of the surface

\footnotetext{
* Corresponding author: vva-imash@yandex.ru
} 
properties up to $1600^{\circ} \mathrm{C}$ was established. In paper [4], the mechanical properties of zirconium ceramics were studied when heated to $2000^{\circ} \mathrm{C}$. It was established that crack resistance increases up to $4.6 \mathrm{MPa} \cdot \mathrm{m}^{1 / 2}$ within the temperature range of $1800-2000^{\circ} \mathrm{C}$; microstructural changes in the surface layer were performed by ultrafast reorientation of carbide silicon. Examination of the surface showed that the mechanical behavior of ceramics under ultrahigh temperature conditions is due to impurities and structural changes [5]. It has been found that the use of materials of higher purity in the synthesis of zirconium ceramic materials can lead to an improvement in strength at high temperatures. Structural compatibility and the effect of the addition of $\mathrm{Y}_{2} \mathrm{O}_{3}$ and $\mathrm{HfO}_{2}$ on the structure and phase composition of $\mathrm{ZrO}_{2}$ powders and ceramics on their basis have been studied by electron microscopy [6]. The possibility of increasing the values of the physicomechanical properties of ceramics based on conventional two-component zirconium by forming ternary systems of the YSZ-Hf type is shown. Zirconium ceramics are promising for a variety of tribological applications. Friction and wear of dental ceramics against natural tooth enamel were studied [7, 8]. Tribological tests were performed under conditions of artificial lubrication with saliva using freshly extracted natural teeth and samples with controlled surface roughness. It was found that the coefficient of friction of the enamel against polished zirconia or porcelain was greater than with friction against the gold-palladium alloy and less than friction against the glass ceramics.

Among zirconium materials, partially stabilized zirconia (PSZ) crystals stand out for their unique combination of strength and tribological properties [9]. During friction, due to the discreteness of the contact of solid bodies, large temperature jumps appear on the areas of actual contact [10]. In crystals based on zirconia, a transformation of structural states occurs upon heating. Zirconia crystals obtained from the melt are thermodynamically nonequilibrium, metastable material, as evidenced by the data of phase analysis [11]. Various additives are introduced to stabilize the structure, including yttrium oxide. Thus, with regard to the composition range corresponding to the content of yttrium oxide from 8 to $35 \mathrm{~mol} . \%$, the conditions of synthesis from the melt are such that the crystals contain only a cubic phase, since according to the state diagram, the polymorphic transition temperature cubic tetragonal phase decreases with an increase in the content of yttrium oxide. The rate of decrease in the temperature of crystals after growth is high, the coefficients of diffusion of cations in materials based on zirconia are very low (especially at temperatures below $1000^{\circ} \mathrm{C}$ ) [12], as a result, the crystals retain the phase composition corresponding to high temperatures. Process modes of crystal synthesis, in particular, the crystal growth rate can also affect the phase composition and, in consequence, the wear characteristics. Due to the high melting point, zirconia based materials are promising for use in friction assemblies operating at high temperatures; however, systemic studies of tribotechnical properties are not enough to clarify the physical nature of friction.

The purpose of this paper is to study the process of film formation on the surface of a zirconia crystals in case of dry friction against high-carbon steel.

\section{Materials and methods}

The investigated friction pair consists of nanostructured partially stabilized zirconia crystals of composition $\mathrm{ZrO}_{2}+(3-15)$ mol.\% $\mathrm{Y}_{2} \mathrm{O}_{3}$ and tool steel U10 A, HRC 49-52 (chemical composition in\% C 0.96-1.034; Si 0.17-0.33; Mn 0.17-0.28; Ni 0.2; S 0.018; P 0.025; Cr 0,2; $\mathrm{Cu} 0.2 ; \mathrm{Fe} \mathrm{0.07)}$. The experiments were performed on a UMT-1 friction machine according to the "disk-finger" scheme in the mode of dry sliding friction. PSZ crystal samples were made in the form of a finger of $5 \times 5 \times 10 \mathrm{~mm}$, and a steel counterface was made in the disk shape. Experiments on the study of the morphology of crystal surfaces were performed using a scanning electron microscopy unit "JEOL 5910 LV". The microhardness of the surfaces 
was measured using a kinetic microhardness tester (microindentation system based on the "MNT-Z-AE-000", a compact platform made by the CSM Instruments).

\section{Results and discussion}

To analyze the interrelation between the parameters of friction and wear of PSZ crystals with their chemical composition and synthesis conditions, it is of interest to study the morphology of friction surfaces and to identify the leading wear mechanisms, such as the destruction of surface layers of samples with different contents of a stabilizing impurity. For this purpose, studies of microhardness, as well as X-ray diffraction and electron-microscopic analysis of the friction surfaces of crystal samples with different contents of stabilizing oxide were performed. Even a visual examination of the friction surfaces after testing shows that they are partially changed in comparison with the initial state, which is associated with the formation of films of secondary structures. The formation of films of secondary structures can be caused by a number of physical and chemical processes, such as frictional transfer of the counterface material, incomplete removal of wear debris from the friction area, their adhesion to the friction surface of the samples, partial or complete oxidation of the transferred material.

Visual inspection of the friction parts revealed the presence of black-blue films on them, covering from 10 to $60 \%$ of the friction surfaces (according to the results of tests of the 8 crystalline samples of the same type). These films were formed due to wear products, which partially remained in the contact area and were firmly adhered to the friction surfaces. At the initial stage of testing the friction assembly, two processes occur simultaneously: running-in and the formation of a steady roughness of the friction surfaces, as well as the formation of wear particles and surface films on friction parts. These films are composed of iron oxides with individual inclusions of microparticles of PSZ crystals and their decomposition products. Usually, iron oxides have antifriction properties that differ from the steel from which they are formed. Therefore, it is logical to assume that the films formed on the friction parts affect the average value of the friction coefficient. Fluctuations in the friction coefficient are associated with the formation and removal of primary and secondary wear particles from the contact area. An indirect assessment of the thickness " $\mathrm{h}$ " of the films formed in the process of testing, on the basis of measuring the microhardness, studies using X-ray diffraction analysis and electron microscopy allows us to conclude that the thickness is in the range of 1.0-3.5 $\mu \mathrm{m}$.

Figure 1 shows the data of an electron microscopic examination of the friction surface of a sample PSZ crystal with 4 mol. $\% \mathrm{Y}_{2} \mathrm{O}_{3}$ at various magnifications.

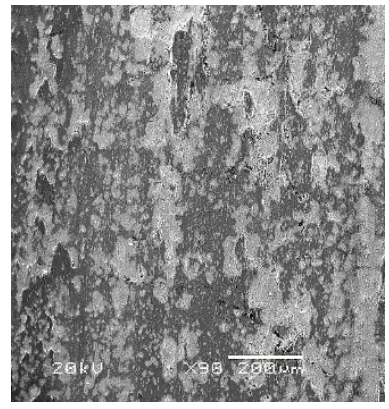

a

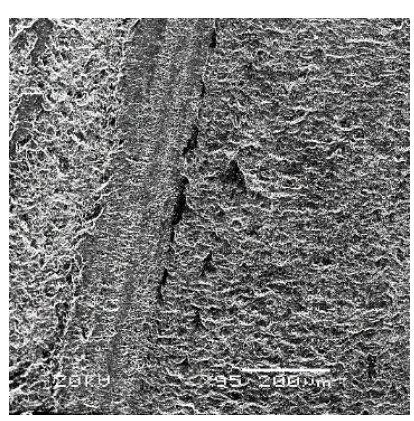

b

Fig. 1. a - secondary structures on the friction surface of sample with 4 mol.\% $\mathrm{Y}_{2} \mathrm{O}_{3}, \mathrm{~b}$ - surface section without films of secondary structures 
It can be seen that there are films (light sections) on the friction surfaces, and the overall picture of the distribution of the films over the surface, the level of continuity of the films, as well as the area of individual film sections are different for samples with various concentrations of the stabilizing oxide. Thus, for samples with a $\mathrm{Y}_{2} \mathrm{O}_{3}$ content of 2 mol.\%, the film is not continuous; it consists of individual sections, most of which oriented in the sliding direction. Darker sections of the sample base material are visible between the fragments of the film. At $4 \mathrm{~mol} . \% \mathrm{Y}_{2} \mathrm{O}_{3}$, the film is also not continuous; however, there is observed an increase in the area of individual film sections and the area covered by the film.

In contrast, at $8 \mathrm{~mol} \% \mathrm{Y}_{2} \mathrm{O}_{3}$, the film is characterized by a high level of continuity. The friction surface of samples with 2-4 mol.\% $\mathrm{Y}_{2} \mathrm{O}_{3}$ almost does not have large systematic cracks, while the film on a sample with $8 \mathrm{~mol} \% \mathrm{Y}_{2} \mathrm{O}_{3}$ is covered with a system of deep cracks located perpendicular to the sliding direction.

To verify the reliability of such a model of friction processes in tribo-conjugation $\left[\mathrm{ZrO}_{2}\right.$ $\left.+3 \mathrm{~mol} . \% \mathrm{Y}_{2} \mathrm{O}_{3}-\mathrm{U} 10 \mathrm{~A}\right]$, it is reasonable to establish and investigate in more detail the chemical composition and frictional properties of surface films in the future. The uneven distribution of the films of secondary structures over the surface is observed. There is also a change in the microhardness of the surface layers after tribological tests. Some data on the change in microhardness "H" are given in Table 1.

Table 1. Microhardness of the friction surface of samples with different content of $\mathrm{Y}_{2} \mathrm{O}_{3}$

\begin{tabular}{|c|c|c|}
\hline \multirow{2}{*}{$\mathbf{Y}_{2} \mathbf{O}_{3}, \mathbf{m o l . \%}$} & $\mathbf{H}, \mathbf{H P a}$ & $\mathbf{H}, \mathbf{H P a}$ \\
\cline { 2 - 3 } & before testing & after testing \\
\hline 0 & 12.10 & 9.13 \\
\hline 3.5 & 15.84 & 9.98 \\
\hline 4.0 & 12.57 & 11.48 \\
\hline 8.0 & 11.83 & 10.9 \\
\hline 15.0 & 10.72 & 9.75 \\
\hline
\end{tabular}

It should be noted that there is a scatter in the values of microhardness on the friction surface, due to both the scatter of the hardness on the initial surface and the inhomogeneity of the microstructure of the surface films. The decrease in microhardness during tribological tests of samples containing up to $3.5 \mathrm{~mol} . \% \mathrm{Y}_{2} \mathrm{O}_{3}$ is obviously associated with the appearance on the sample surface of a monoclinic phase formed during the phase transition of the transformed tetragonal phase under the action of mechanical loads and a local increase in temperature during friction [9]. Due to the mechanism of transformation hardening [13], the number of microcracks on the surface is small and they are of a surface nature, but the microhardness decreases. A smaller change in microhardness is observed with an increase in the concentration of yttrium oxide in the sample. With an increase in the concentration of $\mathrm{Y}_{2} \mathrm{O}_{3}$ in the material, there is a decrease in the content of the transformed $(\mathrm{t})$ tetragonal phase and an increase in the content of the non-transformable $\left(\mathrm{t}^{\prime}\right)$ phase [14]. The high fracture toughness of the non-transformable phase is due to the action of the ferroelastic hardening mechanism [15]. Due to this hardening mechanism, the number of cracks on the sample surface is small, but the microhardness does not significantly decrease, since there is no phase transformation into the monoclinic phase. With an increase in the concentration of yttrium oxide to $8 \mathrm{~mol} \%$ and higher, there is no twinned microstructure in the samples and the crystals have a fluorite cubic structure [11]. In the absence of hardening mechanisms typical for crystals with a tetragonal structure, stresses in the surface layer are removed due to deep cracks and dislocations [16], and the microhardness changes insignificantly.

Analysis of the morphology of the friction surface of PSZ crystal samples with 2-4 mol.\% $\mathrm{Y}_{2} \mathrm{O}_{3}$ shows that the structure of the films is rather homogeneous with traces of boundaries of smaller particles of the transferred material (fig. 2). In some places it is possible to see the 
hair-like cracks, mainly localized within small areas. The accumulation and partial compaction of wear debris is observed in the surface areas between the film sections.

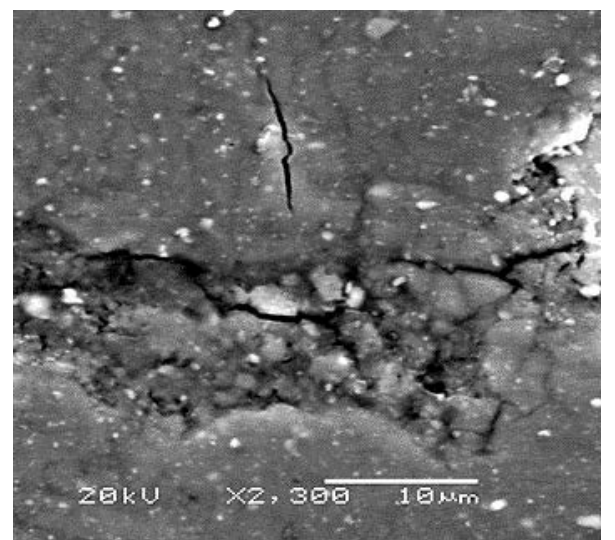

a

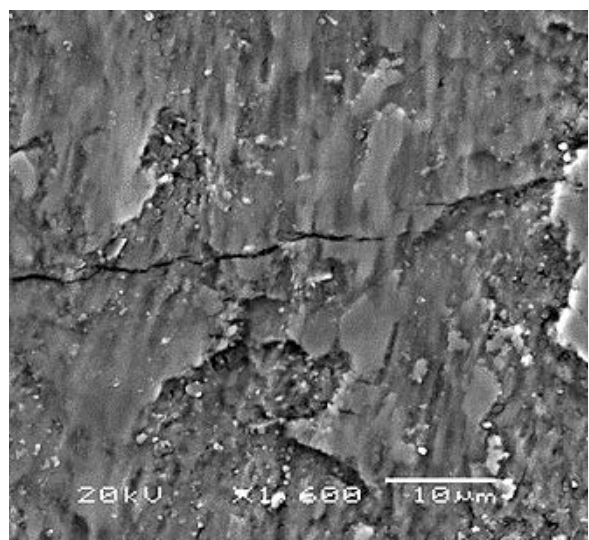

b

Fig. 2. Types of surface destruction of PSZ crystal samples with different contents of stabilizing oxide: $\mathrm{a}-2 \mathrm{~mol} . \% \mathrm{Y}_{2} \mathrm{O}_{3}, \mathrm{~b}-4 \mathrm{~mol} . \% \mathrm{Y}_{2} \mathrm{O}_{3}$

Individual wear particles are also visible on the surface of the films. The films are layered on top of each other, which is especially noticeable on the surface of a sample with 4 mol.\% $\mathrm{Y}_{2} \mathrm{O}_{3}$ (fig. 3).

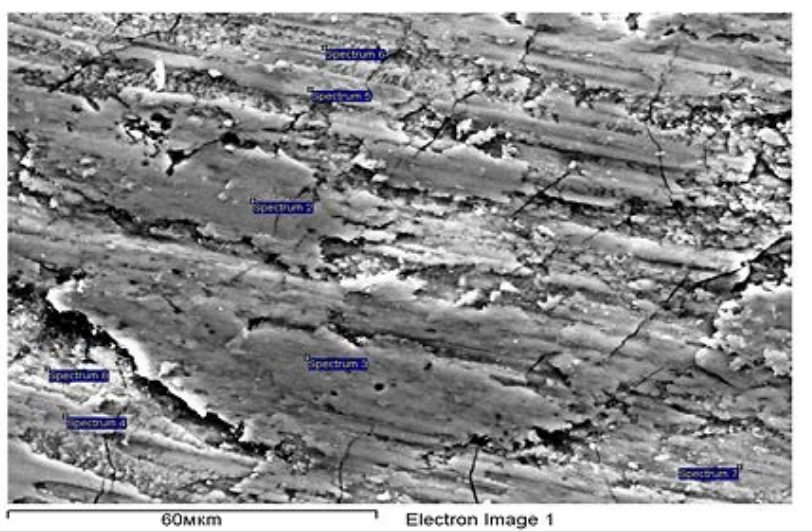

Fig. 3. Friction surface of a sample of $\mathrm{PSZ}$ crystal with $4 \mathrm{~mol} . \% \mathrm{Y}_{2} \mathrm{O}_{3}$ after tests at $\mathrm{p}=5 \mathrm{MPa}$

Table 2 shows the data of elemental analysis of various areas on the friction surface of the $\mathrm{ZrO}_{2}-4$ mol.\% $\mathrm{Y}_{2} \mathrm{O}_{3}$ crystal sample. The points of the surface examination are shown in figure 3 . The absence of yttrium in the chemical composition of transfer films indicates that the films are based on iron oxides. The surface of the PSZ crystal is practically protected from wear.

Table 2. Elemental composition of various sections of the friction surface

\begin{tabular}{|l|c|c|c|c|}
\hline \multicolumn{1}{|c|}{ Area } & $\begin{array}{c}\text { Oxygen (O), } \\
\text { at.\% }\end{array}$ & $\begin{array}{c}\text { Iron (Fe), } \\
\text { at.\% }\end{array}$ & $\begin{array}{c}\text { Zirconium (Zr), } \\
\text { at.\% }\end{array}$ & $\begin{array}{c}\text { Total value, } \\
\text { at.\% }\end{array}$ \\
\hline 1 (homogeneous film) & 61.06 & 32.31 & 6.63 & 100 \\
\hline 2 (wear debris accumulation) & 72.52 & 0.44 & 27.04 & 100 \\
\hline 3 (fuzzy structure) & 75.06 & 9.63 & 15.32 & 100 \\
\hline 4 (wavy-grain structure) & 50.33 & 38.63 & 10.84 & 100 \\
\hline
\end{tabular}


When the PSZ crystal is rubbed against steel, as a result of the frictional interaction of surfaces, a heat flow is formed, which is mainly directed into a material with a higher thermal conductivity, i.e. into steel. As the surface layer heats up, its strength characteristics decrease. The forces of intermolecular interaction between the contacting surfaces are of an electrical nature, therefore, the strength properties of the adhesive bond almost do not change in case of heating. When the strength of the adhesive bond is equal to the strength of the surface layer of the steel sample, the transfer of film to the surface of the PSZ crystal occurs, forming a "third body". A film on the crystal surface protects the crystal sample from wear. With further heating of the film, it burns out forming a sheaf of sparks and the process is repeated. By changing the parameters of friction, it is possible to adjust the frequency of emission of a sparks sheaf. Essentially, with this phenomenon, the crystal almost does not wear out, but the friction surface of the steel wears out strongly. In this case, the friction mode should be considered catastrophic. The possibility of the formation of the ejection effect of the droplet phase of the molten metal must be taken into account when designing machines.

Analysis of the morphology of surface secondary structures allows us to conclude that the destruction of the surface layers of samples with 2 and 4 mol.\% $\mathrm{Y}_{2} \mathrm{O}_{3}$ occurs primarily by way of local destruction and peeling of the surface films. During friction, in addition to wear itself (material separation from the surface), low-cycle fatigue processes occur, which are associated with the gradual accumulation of damage both in the film of secondary structures and in the matrix material and are responsible for wear. Thus, it can be assumed that the wear mechanism should include two stages: destruction of the surface layer of secondary structures and destruction in deeper layers of the base material.

\section{Conclusions}

Analysis of the microstructure of the friction surface of the PSZ crystal samples after tribological tests has been performed. It is shown that the friction surface is morphologically inhomogeneous, includes various localized areas characterized by different elemental composition, structure and microhardness. It is shown that during testing, films of secondary structures are formed on the friction surface of PSZ crystals, which is visually appeared in a change in the color of the friction surfaces. The formation of these films is caused by the development of a number of physicochemical and mechanical processes, which include:

- frictional transfer of the counterface material to the surface of the PSZ crystal samples;

- incomplete removal of wear debris from the contact area, their adhesion to the friction surface of the samples and their incremental compaction and densifying;

- partial or complete oxidation of the transferred material, etc.

In the contact area, these films are distributed in form of separate uneven spots, elongated in the direction of the sliding velocity vector and covering from $10 \%$ to $60 \%$ of the nominal contact area. With an increase in the $\mathrm{Y}_{2} \mathrm{O}_{3}$ concentration in PSZ crystals, the thickness and continuity of the films increase.

The mechanics of surface fracture of PSZ crystals depends on the $\mathrm{Y}_{2} \mathrm{O}_{3}$ content. If the amount of $\mathrm{Y}_{2} \mathrm{O}_{3}$ does not exceed 4 mol.\%, then the wear processes are localized mainly in the layer of secondary structures. If the amount of $\mathrm{Y}_{2} \mathrm{O}_{3}$ is $\geq 8 \mathrm{~mol} . \%$, then the crystals become single-phase cubic and the destruction of the surface layers of the crystals also affects the underlying layers of the base material. They do not have the nanocrystalline structure, which formed as a result of the polymorphic transformation of the cubic phase to the tetragonal one. In single-phase cubic single crystals, the brittleness increases significantly, which contributes to an increase in wear.

Based on the results of the studies, it was assumed that the wear mechanism of PSZ crystals is predominantly mechanical (fatigue) in nature and includes two stages, namely destruction of the surface layer of secondary structures and destruction in deeper layers of 
the matrix material. At both stages, the surface films of secondary structures play a significant role in the wear processes.

The work was supported by research grants No. 18-13-00397 of the Russian Science Foundation.

\section{References}

1. N.L. Savchenko, Yu.A. Mironov, A.S. Buyakov, A.G. Burlachenko, S.Yu. Tarasov, Wear, 446-447, $2 \mathrm{O} 3204$ (2020)

2. G-J. Zhang, D-W. Bi, J.Z. Zou, H-T. Liu, Y. Sakka, J. Eur. Ceram. Soc., 38(2), pp. 371389 (2018)

3. C. Liu, R. Pan, C. Hong, X. Chang, S. Du, J. Eur. Ceram. Soc., 36, pp. 395-402 (2016)

4. D'Angio, J. Zou, J. Binner, H-B. Ma, W.G. Fahrenholtz, J. Eur. Ceram. Soc., 38, pp. 391-402 (2018)

5. W. E. Neuman, E.G. Hilmas, W.G. Fahrenholtz, J. Eur. Ceram. Soc., 35, pp. 463-476 (2015)

6. D.R. Belichko, T.E. Konstantinova, A.V. Maletsky, N. Cornei. Influence of hafnium oxide on the structure and properties of powders and ceramics of the YSZ-HfO2 composition, Ceramics International (to be published)

7. L. Wang, Y. Liu, W. Si, H. Feng, Y. Tao, Z. Ma, J. Eur. Ceram. Soc., 32(11), pp. 25992606, (2012)

8. A. Borrell, L. Gil, A. Presenda, M.D. Salvador, J. Vleugels, R. Moreno, Wear, 428-429, pp. 1-9, (2019)

9. M.A. Borik, V.P. Borichevskij, V.T. Bublik, A.V. Kulebyakin, E.E. Lomonova, F.O. Milovich, V.A. Myzina, P.A. Ryabochkina, N.V. Sidorova, N. Yu. Tabachkova, J. Alloys Compd., 792, pp. 1255-1260 (2019)

10. Yu.N. Drozdov, E.G. Yudin, A.I. Belov. Applied tribology (friction, wear, lubrication) (Eco-Press, Moscow, 2010)

11. M.A. Borik, S.I. Bredikhin, V.T. Bublik, A.V. Kulebyakin, I.E. Kuritsyna, E.E. Lomonova, F.O. Milovich, V.A. Myzina, V.V. Osiko, P.A. Ryabochkina, N.Yu. Tabachkova, T.V. Volkova. Materials Letters. 205. pp. 186-189 (2017)

12. Y. Dong, L. Qi, J. Li, I.W. Chen Acta Materialia, 126 pp. 438-450 (2017)

13. A. H. Heuer, M. Rühle, and D. B. Marshall, J. Am. Ceram. Soc., 73, 4, pp. 1084-1093 (1990)

14. M.A. Borik, V.T. Bublik, A.V. Kulebyakin, E.E. Lomonova, F.O. Milovich, V.A. Myzina, V.V. Osiko, N.Yu. Tabachkova, J. Alloys Compd. 586. pp. 231-235. (2014)

15. B. Basu, International Materials Reviews, 50, 4, pp. 239-256. (2005)

16. B. Baufeld, D. Baither, U. Messerschmidt, Phys. Status Solidi (a), 150, pp. 1297-306 (1995) 